\section{Dr. Skogh, et al, reply}

\section{To the Editor:}

We thank Dr. Jearn and colleagues for their interest in our article on abnormal serum titers of antinuclear antibodies (ANA) assessed by means of immunofluorescence (IF)-microscopy [i.e., one of the 11 American College of Rheumatology (ACR) classification criteria from 1982] with HEp-2 cells as the source of nuclear antigens. We reported that only $76 \%$ of patients with an established diagnosis of systemic lupus erythematosus (SLE) had abnormal serum titers of ANA, although all patients had been judged ANA-positive at the time of diagnosis. Jearn, et al do not raise any objections against our results or our conclusions, but claim that "it has a potential threat in questioning the basic pathogenesis of SLE, which is destined to possess ANA." Exactly what they imply by this is not obvious to us. However, they also give several statements based on their conviction that it was a great mistake from the start to exploit HEp-2 cells (a human laryngeal carcinoma cell line) for IF-ANA analysis. Instead, they advocate the use of a human nonmalignant macrophage cell line, IT-1. By this approach, 2 Korean studies have reported positive ANA in $100 \%$ of patients with SLE. However, the only one published as a PubMed-indexed report in English reported that all sera out of 588 from patients with SLE (according to the 1982 ACR criteria) tested ANA-positive on IT-1 cells ${ }^{1}$. Unfortunately, the cutoff level for an abnormal ANA titer was not defined! As in many other reports, the lack of a defined abnormal antibody level is an unfortunate limitation in the study by Sung, et $a l^{1}$.

An IT-1 cell assay has recently been commercialized in Korea under the name of "autoimmune target (AIT) test." Apart from a brief report in the Weekly Han Yang No.3, June 2007 (http://www.hanyang.ac.kr/ week/2007/200706/e3_sub2-N.html), we have not found anything written in English about this commercial assay. In their letter, Dr. Jearn, et al present data from 234 healthy blood donors, of which only $8.4 \%$ (!) tested ANA-positive with the AIT test at a serum dilution of 1:40 (3.4\% representing the "MOTC-pattern," which they claim does not occur in SLE). The subsequent discussion regarding data presented in Table 2 is hard to follow. This concerns 570 AIT-tested serum samples, all of which were judged ANA-negative on HEp-2 cells (serum dilution 1:40?). It is not stated on what premise the samples were taken (suspected SLE or other disease states?), but $48 \%$ of the HEp-2 ANA-negative sera obviously tested positive in the AIT test (serum dilution 1:40?). Even at higher dilutions, a considerable number of patients were AIT-positive, although it appears that many of the results refer to extranuclear staining patterns. This was seen also in early limited studies on the IT-1 cell line in Denmark, and was a main reason to refrain from the use of it for ANA diagnostics (Dr. Allan Wiik, personal communication). Despite the Korean results reported thus far, the documentation is very limited compared to the endless number of reports on ANA testing with HEp-2 cells. Additional ambitious studies on well defined patient materials and healthy controls have to be performed also outside Korea, comparing abnormal levels of ANA/Hep-2 with ANA/IT-1, and the results must be published in English in international peer-reviewed journals. Until this has been accomplished, HEp-2/HEp-2000 cells must, of course, remain the gold standard ${ }^{2}$. Importantly, as we conclude in our report, positive results should be reported using a cutoff limit defining abnormal serum levels of ANA $^{3}$.

THOMAS SKOGH, MD, PhD, Rheumatology Unit/AIM; ANDERS A. BENGTSSON, MD, PhD, Clinical Immunology Unit/AIM, Department of Clinical and Experimental Medicine, Linköping University Hospital, Linköping; CHARLOTTE DAHLE, MD, PhD, Department of Rheumatology, Clinical Sciences, Lund University Hospital, Lund; ANDREAS JÖNSEN, MD, PhD, Clinical Immunology Unit/AIM; CHRISTOPHER SJÖWALL, MD, PhD, Rheumatology Unit/AIM; GUNNAR STURFELT, MD, PhD, Clinical Immunology Unit/AIM; MARTIN STURM, MD, Rheumatology Unit/AIM, Department of Clinical and Experimental Medicine, Linköping University Hospital, SE-581 85 Linköping, Sweden. Address reprint requests to Dr. Skogh;

E-mail: thomas.skogh@lio.se

\section{REFERENCES}

1. Sung YK, Hur NW, Sinskey JL, Park D, Bae SC. Assessment of damage in Korean patients with systemic lupus erythematosus. J Rheumatol 2007;34:987-91.

2. Dahle C, Skogh T, Åberg AK, Jalal A, Olcén P. Methods of choice for diagnostic antinuclear antibody (ANA) screening: benefit of adding antigen-specific assays to immunofluorescence microscopy. J Autoimmun 2004;22:241-8.

3. Sjöwall C, Sturm M, Dahle C, et al. Abnormal antinuclear antibody titres are less common than generally assumed in established cases of systemic lupus erythematosus. J Rheumatol 2008;35:1994-2000.

J Rheumatol 2009;36:8; doi:10.3899/jrheum.090260 